\title{
Evaluating a Fish Monitoring Protocol Using State-Space Hierarchical Models
}

\author{
Robin E. Russell ${ }^{1 *}$, David A. Schmetterling ${ }^{2}$, Chris S. Guy ${ }^{3}$, Bradley B. Shepard ${ }^{2, \#}$, Robert McFar- \\ land $^{1}$, and Donald Skaar ${ }^{4}$ \\ ${ }^{1}$ Montana Fish, Wildlife and Parks, 3201 Spurgin Road, Missoula, MT 59801, USA \\ ${ }^{2}$ Montana Fish, Wildlife and Parks, 1400 S. 19th Ave, Bozeman, MT 59718, USA \\ ${ }^{3}$ US Geological Survey, Montana Cooperative Fishery Research Unit, Montana State University, Bozeman, \\ MT 59715, USA \\ ${ }^{4}$ Montana Fish, Wildlife and Parks, 1420 East 6th Ave, Helena, MT 59620, USA
}

\begin{abstract}
Using data collected from three river reaches in Montana, we evaluated our ability to detect population trends and predict fish future fish abundance. Data were collected as part of a long-term monitoring program conducted by Montana Fish, Wildlife and Parks to primarily estimate rainbow (Oncorhynchus mykiss) and brown trout (Salmo trutta) abundance in numerous rivers across Montana. We used a hierarchical Bayesian mark-recapture model to estimate fish abundance over time in each of the three river reaches. We then fit a state-space Gompertz model to estimate current trends and future fish populations. Density dependent effects were detected in 1 of the 6 fish populations. Predictions of future fish populations displayed wide credible intervals. Our simulations indicated that given the observed variation in the abundance estimates, the probability of detecting a $30 \%$ decline in fish populations over a five-year period was less than $50 \%$. We recommend a monitoring program that is closely tied to management objectives and reflects the precision necessary to make informed management decisions.
\end{abstract}

Keywords: Bayesian, Gompertz models, Montana, Oncorhynchus mykiss, Salmo trutta, Trout.

\section{INTRODUCTION}

Trout fishing is an important economic activity in many western states including Montana [1]. Over the past 20 years Montana's rivers have been influenced by many factors including cessation of fish stocking, terminal gear and harvest restrictions, variable flow and temperature regimes due to dam operations and climate fluctuations [2], and whirling disease (Myxobolus cerebralis) [3]. In Montana, fish populations are monitored as "surveillance" i.e., monitoring that is not driven by a priori hypotheses and alternative models of ecosystem processes [4]. Long-term data sets monitoring populations may be useful for estimating the effects of changing environmental conditions or human manipulations of the environment, and providing baselines to evaluate future responses [5]. However, recent literature has suggested that long-term monitoring driven by statistical rigor, carefully defined questions, and conceptual models of ecosystem processes can more efficiently provide information that is directly relevant to management concerns and issues [4-5].

Effective monitoring programs for fish and wildlife provide managers with information needed to make informed

*Address correspondence to this author at US Geological Survey, 6006 Schroeder Rd, Madison WI, 53711, USA; Tel: 608-2742474;

Fax: 608-270-2415; E-mail: rerussell@usgs.gov

\#Current address: Wildlife Conservation Society, 301 North Willson Avenue, Bozeman, Montana 59715; USA decisions regarding management actions [6]. Fish and wild life managers monitor populations and use long-term data to inform the public, evaluate impacts of environmental changes, and assess population status to determine if management actions are necessary to sustain population levels. Despite the value of long-term data sets, estimating population abundance is often a time-consuming and complex task and data are often equivocal or imprecise. Natural environmental and demographic stochasticity can mask population changes that may be important for informing management decisions [7]. Several recent studies describe and recommend the use of modeling procedures that make more accurate inferences and predictions regarding population dynamics because they account for observation error produced by an observer's inability to perfectly detect and measure the system (i.e., capture efficiency) [7-9].

Mark-recapture methods [10-11] are commonly used to estimate the abundance of fish and wildlife populations. Fish populations may violate closure assumptions due to movements [12], thus biasing density estimates high. However, if animal movements are random in and out of the study population, abundance estimates are less precise but unbiased [13]. Hierarchical models represent a powerful approach for incorporating ecological uncertainty and accounting for both observation and process error when modeling populations [14]. When analyzing long-term time-series data sets, accounting for variability in detection probabilities over time (observer error) is important to prevent interpreting changes in detectability as though they were changes in population 
size [15]. Incorporating observation error of population estimates into modeling of the time-series data is an important step to ensure that uncertainty is included in any analysis of trend. Only models that contain both process and observation error can fully capture the range of uncertainty associated with complex ecological studies [9].

We evaluate the ability of Montana Fish Wildlife and Parks' surveillance monitoring program to address trout management issues in Montana rivers. We estimate the observation error for trout abundance from mark-recapture models [16], and then incorporate estimates of observation error into a process model (in our case a Gompertz model) to estimate population trend, predict populations into the future and estimate their risk of decline, and evaluate the effects of surveying fish populations in alternative years rather than annually on our estimates of populations trend and potential for a population decline. Lastly we estimate the ability of the monitoring programs to detect short-term trend in fish populations based on observed variation.

\section{MATERIALS AND METHODS}

\subsection{Mark-Recapture Data}

The data used for this analysis were collected by Montana Fish, Wildlife \& Parks (FWP) between 1988 and 2008. For this study we selected river reaches in three major rivers in Montana based on the availability of relatively complete data sets for the 20 year period; the Mill Creek section of the Yellowstone River, Pine Butte section of the Madison River, and the Craig section of the Missouri River. These monitoring reaches were initially established based on ease of access, few safety hazards, the presence of habitats and fish communities that represented much longer reaches of each river, and where fisheries biologists could reasonable expect a uniform fish capture efficiency across the study area (i.e., no hard to access areas).

Sampling was conducted to fulfill the assumptions of a closed population associated with the Peterson [10] markrecapture estimator $[17,18]$. However, because of the difficulties monitoring species in unbounded reaches (i.e., without block nets or barriers), care was taken to maximize capture efficiency and these conditions were mimicked among years. Conditions biologists attempted to control for included water conditions (i.e., river stage, turbidity, temperature) and timing of sampling for when target species were relatively sessile (e.g., i.e., reduce effects of movement into and out of sample sections [13]).

Population sampling was conducted either in the spring (May-June) on the Yellowstone or the fall (AugustSeptember) on the Madison and Missouri rivers. Sampling each year was conducted in as similar conditions (i.e., flow, turbidity, water temperature, and time of year) as possible to limit annual variation in capture efficiencies and fish behavior caused by environmental variation at the time of sampling. Crews generally made between two and three downstream marking runs.

Sampling was conducted using a drift boat with a mobile anode on the Madison River, and jet-powered boats with boom-mounted anodes on the Yellowstone and Missouri rivers. During marking runs, all trout were anesthetized (using MS-222), measured for total length (to the nearest 2.5 $\mathrm{mm}[0.1 \mathrm{inch}]$ ), weighed (to the nearest $4.5 \mathrm{~g}$ [0.01 pound]), and marked with a fin clip that could be easily recognized upon recapture. Following handling, fish were released back into the sampling section near where they were captured. Electrofishing was conducted with straight DC, and typically around 1,000 watts was used for capture to reduce spinal injury $[19,20]$. Recapture runs were made within 7 - 10 days of the marking runs to limit growth and movement, while allowing enough time for the fish to redistribute within the population and recover from handling [21-23].

\subsection{Mark-Recapture Model}

We follow Royle and Dorazio [16] and formulate our recapture data as a multinomial distribution with the number of outcomes equal to the number of possible binary encounter histories. For example, with two visits there are four possible outcomes $(11,10,01,00)$ and the probabilities are $\pi_{11}=p^{2}$, $\pi_{10}=p(1-p), \pi_{01}=(1-p), \pi_{00}=(1-p)^{2} ;$ where $\mathrm{p}=$ the capture rates or probability of animal being included in sample. Capture rates in fish can vary from individual to individual due to the species and size of the fish, and can vary from year to year due to crew efficiency, seasonal timing of surveys, water clarity, and other factors. Therefore, estimates that correct for the imperfect "catchability" of all animals in the population are likely to be more accurate.

Incorporating known or suspected effects on recapture probabilities is an important step in obtaining unbiased estimates of abundance, particularly if changes in detection may mask or distort the comparisons of interest [24]. We model the effect of fish size and year hierarchically by imposing a prior distribution, a hyperprior, on the collection of parameter estimates. The prior distribution of the covariate effects (year and fish size) on detection probability (p) are defined by a normal distribution $(\mu, \tau)$ with a mean $(\mu)$ and a standard deviation $(\tau)$. The prior distribution of $\tau \sim\left(1 /\left(\sigma^{2}\right)\right)$, and the prior distribution of $\sigma=\mathrm{N}(0,2)$. The prior distribution on the $\tau$ is referred to as the hyperprior [25]. Alternatively we could have estimated one parameter for each year and length class resulting in 20 year specific estimates and 3 independent length class estimates. We could also have assumed a constant detection probability across time and length class and ignored variability in detection. Modeling the parameters hierarchically in essence is a compromise between these alternative model constructions. The hierarchical construct results in a "borrowing" of information across parameters drawn from the same population, in our case detection probabilities estimated from replicate years of data on the same fish population.

We carried out a Bayesian analysis of the markrecapture model using the method of data augmentation. Data augmentation is achieved by augmenting the observed data set with a large number of all-zero encounter histories [26], in effect creating a "superpopulation" of individuals, $M$, where only a subset of those individuals, $N$, are exposed to sampling. A set of latent indicator variables $z_{i}(i=1,2, M)$, determines which individuals in $M$ are members of $N$. Membership of an individual is determined by a Bernoulli trial where $z_{i} \sim \operatorname{Bern}(\psi) ; z_{i}=1$ if the individual $i$ is a member of 
the population and $z_{i}=0$ if the individual is not, and $\psi$ is the overall probability that an individual in $\mathrm{M}$ is a member of $\mathrm{N}$.

Population size is defined as a function of the latent $\mathrm{z}$ variables according to

$N=\sum_{i=1}^{M} z_{i}$

where $N$ prior is formulated as a binomial $N \sim \operatorname{Bin}(M, \psi)$

The observation model (i.e., for $y_{i}$ ) is defined conditional on the latent variables $z_{i}$ :

$y_{i} \sim \operatorname{Bin}\left(J, z_{i} p\right)$.

We modify $\mathrm{p}$ in our models to reflect capture efficiency as a function of trout length class (s) $(25.4 \mathrm{~cm}$ to $<30.5 \mathrm{~cm}$, $30.5 \mathrm{~cm}$ to $<38.1 \mathrm{~cm}$, or $\geq 38.1 \mathrm{~cm})$ and year $(t)$;

$\operatorname{logit}\left(\mathrm{p}_{\mathrm{s}, \mathrm{t}}\right)=\eta_{\mathrm{s}}+\beta_{\mathrm{t}}$

Further year and length class are modeled as a normally distributed random effects where $\beta \sim \operatorname{norm}\left(0, \tau_{\beta}\right)$, $\tau_{\beta}=\sigma_{\beta}^{2}$ and $\sigma_{\beta} \sim U(0,5)$ and $\eta \sim N\left(\mu_{\eta}, \tau_{\eta}\right)$, with $\mu_{\eta} \sim N(-$ $1.7,4), \tau_{\eta}=\sigma_{\eta}^{2}$ and $\sigma_{\eta} \sim U(0,2)$.

The prior on $\mu_{\eta}$ was determined by previous research modeling the effects of all length classes including those less than $25.4 \mathrm{~cm}$ on recapture efficiencies (J. Robinson-Cox pers. comm.). We implemented the model in WINBUGS for 15,000 iterations and saved every $5^{\text {th }}$ iteration of 3 chains, discarding the first 4000 iterations as "burn-in". Models generally took 8-20 hours to run depending on the size of the fish population. We evaluated models for adequate convergence based on visual inspection of the chains and on $\widehat{R}<$ $1.2[23]$.

\subsection{Population Models}

Bayesian state-space models with observation error and process error were used for predicting populations into the future and estimating trend where $\mathrm{X}_{t} \sim N\left(\mathrm{~N}_{t}, \tau_{x}\right)$; where $\mathrm{X}_{t}$ is the estimated abundance of the population at time $t$ from the mark-recapture models, $\mathrm{N}_{t}$ is the true populations size, and $\tau_{x}$ is the estimated error on the abundance of fish at time $t$ also from the mark-recapture models. For our process model we used the Gompertz model

$\log \left(N_{t}\right)=\log \left(N_{t-1}\right)+\alpha+\beta_{1} * \log \left(N_{t-1}\right)+\varepsilon_{t}$

where $\varepsilon_{t}$ is a normal distributed error term representing the process error. This was a two-stage process, where population estimates were made from mark-recapture models, and then Gompertz models were applied to the estimates. We selected the Gompertz model because we believed, after much discussion with fisheries biologists, Gompertz models adequately represent fish populations constrained by some type of density-dependent process in a river system [27]. Additionally, previous studies on these same systems have determined that Gompertz models best represent fish count data for bull trout populations [28]. Gompertz models are similar to Ricker models another commonly used model for fish population growth. Ricker models assume that there is a linear decrease in the growth rate as a function of population size [29], while Gompertz models assume a linear decrease in the growth rate as a function of the $\log$ of the population size. As a result, density dependent effects are larger at small population sizes under the Gompertz model assumption that the Ricker model. Recent research has indicated that for a pelagic species decline in a San Francisco Estuary, both models gave similar inferences but the Gompertz model identify more relationships with covariates [30].

We evaluated the strength of density dependence by simulating density independent population growth by using the posterior distributions of the estimate $\alpha$ and $\mathrm{N}$ from WinBUGS simulations and setting the $\beta$ terms in the Gompertz models to zero to create a null hypothesis population [31]. We calculated the mean and 95\% credible interval for the difference between the population estimate assuming density independence (i.e $\beta=0$ ) and the population estimate with density dependence (i.e $N_{t}$ the predicted values from Gompertz models).

We evaluated goodness of fit by visually assessing the relationship between the log of the mark-recapture estimates versus the $\log$ of the estimates generated by the Gompertz models.

\subsection{Evaluation of Alternate Year Sampling}

In order to evaluate whether years could be skipped and the impact this would have on our ability to detect or interpret trends in the populations, we fit a Gompertz model to abundance estimates from mark-recapture models for rainbow and brown trout over a 20 year period. Our model predictions were calculated automatically in WinBUGS by assigning NA to $X_{\mathrm{t}}$ where $\mathrm{t}>20$. We compared observed data to our predictions to assess model fit. We then evaluated the effect of surveying fish populations in alternative years rather than annually by assigning a value of NA to alternate years of observation data and re-fitting the Gompertz models.

We estimated the potential for a population decline, by assessing the 6600 predicted abundance estimates (from running 3 chains for 15,000 with a burn-in of 4000 and a thinning rate of 5) for the years where $t>20$ to determine the percentage of estimated abundances that fell below $30 \%$ of the mean value of the previous 20 years. We estimated the probability of a population decline from models containing all data and models containing alternate years of data to compare predictions between models. We selected a 30\% decline in the population as a threshold because we believed that a decline of this magnitude would trigger a reaction from the public, and may be empirically obvious (Montana Fish, Wildlife and Parks Monitoring Evaluation committee).

\subsection{Trend Detection}

We evaluated our ability to detect a $30 \%, 50 \%$, and $75 \%$ decline in fish populations over a 5-year period. We started a population at its mean value over the observed time period, and generated data representing a 5 year trend line with a $30 \%, 50 \%$,or $75 \%$ decline. Each observed value in the trend was modeled as $X_{t} \sim N(\mu, \sigma)$ with $\mu$ equal to the true value of the observation $\left(N_{t}\right)$, and observation error $\sigma$ equal to a 

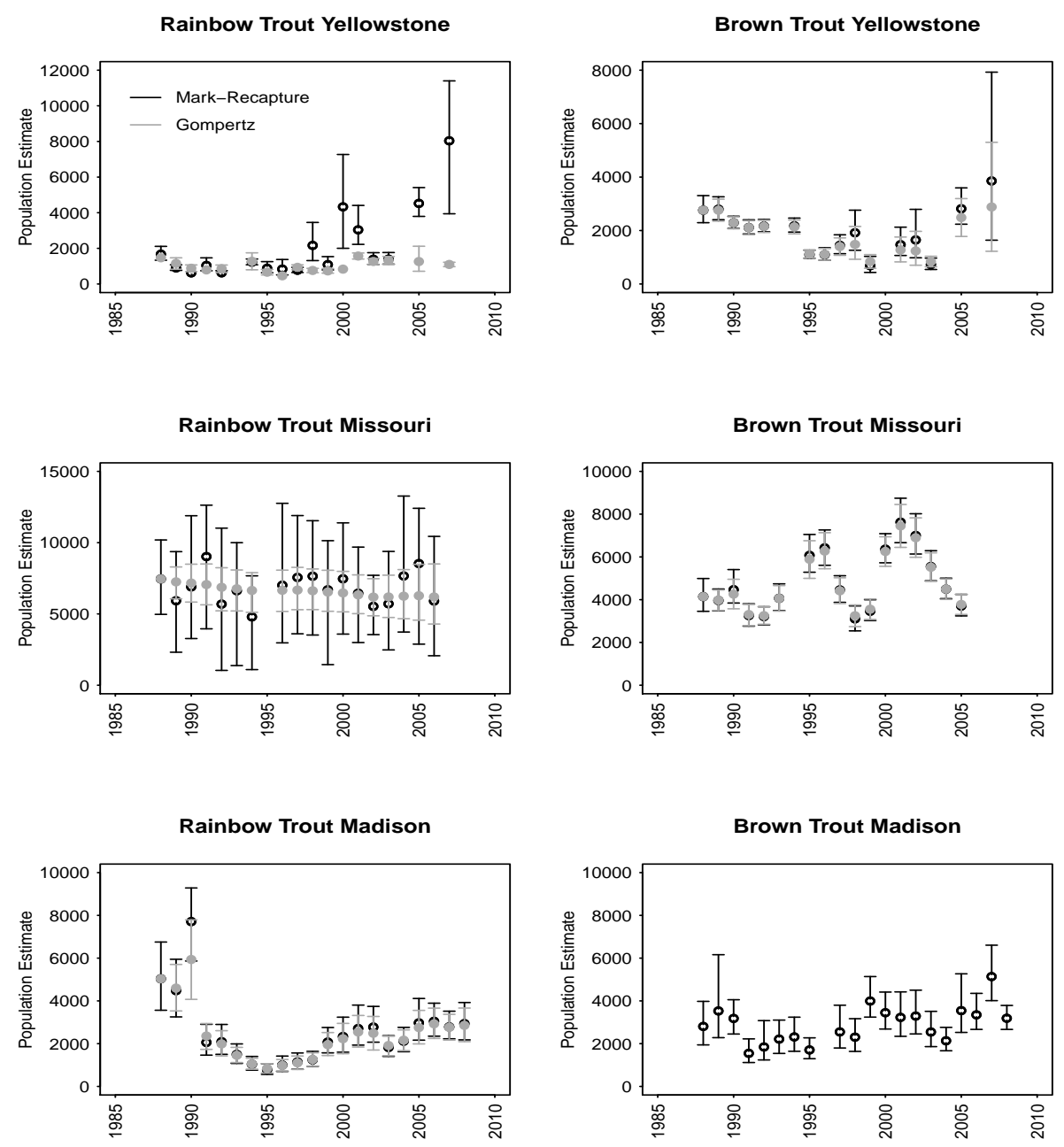

Fig. (1). Estimated brown and rainbow trout abundance in three river reaches in Montana from mark-recapture data (open circles) and predicted trout abundance from Gompertz models (grey dots). Dashed lines represent $95 \%$ credible intervals.

randomly selected coefficient of variation from the observed data. We used the same modeling framework as described above for fitting the Gompertz model, except we used a linear function for the process model

$\log \left(N_{t}\right)=\log \left(N_{t-1}\right)+\alpha+\varepsilon_{t}$

and evaluated the $80 \%$ credible interval of $\alpha$ (the trend) to determine if the interval contained zero.

\section{RESULTS}

\subsection{Evaluation of Trend and Alternate Year Sampling}

The risk of a population declining more than $30 \%$ from a 20-year average, as estimated from our population trajectories, varied from $2 \%$ for rainbow trout in the Missouri River to $43 \%$ for brown trout in the same river (Table 2). Detection probabilities estimated from the Mark-recapture models with data augmentation varied from 0.08-0.20. Population trajectories calculated from replacing alternate years of data with predicted estimates from the Gompertz models generally resulted in similar estimates of risk, with the exception of brown trout in the Yellowstone River. Estimated risk jumped from $32 \%$ to $70 \%$ for this species when alternate years of data were used. Despite adjusting of prior distributions, and numerous attempts, we did not achieve convergence for brown trout populations in the Madison River (i.e. R-hat values $>2$ for all parameters).

Our visual inspections of goodness-of-fit revealed adequate fits for 3 of the 5 populations where we achieved convergence. For rainbow trout on the Missouri and Yellowstone rivers, Predicted values from the Gompertz models indicated that for high and low Mark-Recapture estimates, predicted estimates from the Gompertz models were close to the mean (Fig. 1).

The $95 \%$ credible interval for the density dependent parameter did not overlap zero for brown trout on the Missouri river reach only (Table 1). Additionally, we determined that population estimates were statistically different for DI versus DD predictions for brown trout in same river reach (Fig. 2). For rainbow trout on the Missouri, predicted values from the DD models were consistently lower than predictions from the DI models, but this effect was not statistically significant.

\subsection{Trend Detection}

We estimated that fish populations would have to decline more than $50 \%$ in five years in order to have a $25 \%$ chance or greater of detecting a statistically significant trend 
Table 1. Parameter Estimates from Gompertz State-Space Model where ( $\alpha=$ the Time Trend, $\beta=$ the Density Dependent Effect, and $\varepsilon=$ Process Error) for Three River Reaches in Montana. Data Were Collected Over a 20-Year Period from 1988-2008. L.C.I. and U.C.I. Indicate Upper and Lower $80 \%$ Bayesian Credible Intervals

\begin{tabular}{|c|c|c|c|c|c|c|c|c|}
\hline \multirow[b]{2}{*}{ River } & \multirow[b]{2}{*}{ Species } & \multirow[b]{2}{*}{ Parameter } & \multicolumn{3}{|c|}{ All Years of Data } & \multicolumn{3}{|c|}{ Alternate Years of Data } \\
\hline & & & Mean & L.C.I. & U.C.I. & Mean & L.C.I. & U.C.I. \\
\hline \multirow[t]{6}{*}{ Missouri } & brown & $\alpha$ & -0.162 & -0.393 & 0.027 & 0.007 & -0.389 & 0.327 \\
\hline & & $\beta$ & -0.035 & -0.049 & -0.009 & -0.032 & -0.049 & -0.007 \\
\hline & & $\varepsilon$ & 0.465 & 0.153 & 0.748 & 0.268 & -0.166 & 0.787 \\
\hline & rainbow & $\alpha$ & -0.050 & -0.449 & 0.450 & -0.431 & -0.498 & -0.294 \\
\hline & & $\beta$ & -0.023 & -0.096 & 0.049 & -0.093 & -0.100 & -0.076 \\
\hline & & $\varepsilon$ & 0.241 & -0.187 & 0.674 & 1.245 & 1.099 & 1.381 \\
\hline \multirow[t]{6}{*}{ Yellowstone } & brown & $\alpha$ & -0.009 & -0.381 & 0.369 & -0.067 & -0.385 & 0.367 \\
\hline & & $\beta$ & -0.006 & -0.048 & 0.042 & -0.018 & -0.049 & 0.026 \\
\hline & & $\varepsilon$ & 0.049 & -0.363 & 0.554 & 0.181 & -0.458 & 0.632 \\
\hline & rainbow & $\alpha$ & 0.075 & -0.310 & 0.321 & 0.097 & -0.297 & 0.384 \\
\hline & & $\beta$ & -0.012 & -0.047 & 0.034 & -0.016 & -0.049 & 0.049 \\
\hline & & $\varepsilon$ & -0.011 & -0.408 & 0.307 & -0.007 & -0.436 & 0.378 \\
\hline \multirow[t]{3}{*}{ Madison } & rainbow & $\alpha$ & -0.374 & -0.699 & -0.029 & -0.598 & -0.776 & -0.380 \\
\hline & & $\beta$ & -0.019 & -0.049 & 0.026 & -0.027 & -0.049 & 0.011 \\
\hline & & $\varepsilon$ & 0.486 & 0.197 & 0.769 & 0.804 & 0.297 & 1.148 \\
\hline
\end{tabular}

Rainbow Trout Yellowstone

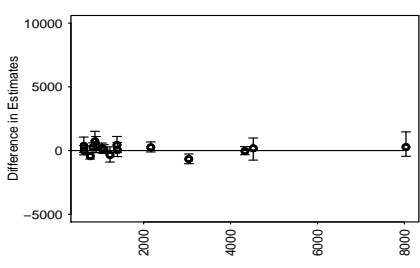

Rainbow Trout Missouri

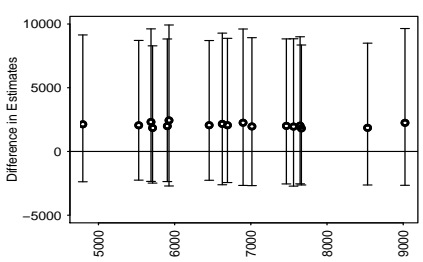

Brown Trout Yellowstone

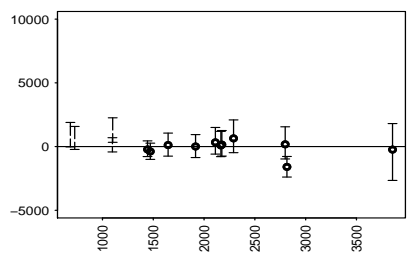

Brown Trout Missouri

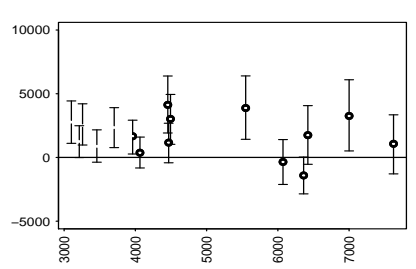

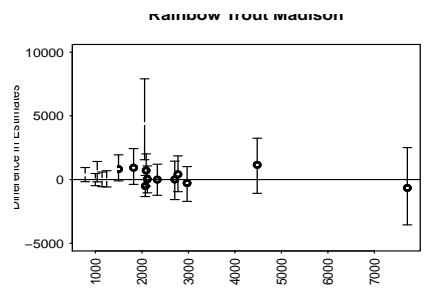

Fig. (2). Estimated difference between predicted population size under density independence and density dependence. Error bars represent $95 \%$ credible intervals. Positive differences indicate that density independent predictions were greater than density dependent predictions, vice versa for negative differences.

(Table 3). The chance of detecting a $75 \%$ decline was approximately $90 \%$ for 5 of 6 populations. For 4 of 6 populations the chance of detecting a $30 \%$ decline was approximately $30 \%$. In general, populations where abundance estimates are more tightly estimated will be more conducive to detecting smaller changes in population size. Therefore, the result that trends were more easily detected in the brown trout population on the Madison where coefficients of variation ranged from 5-9\% was not surprising.

\section{DISCUSSION}

Staples et al., [32] found that trends in annual predictions of risk appeared to be a better indicator than actual trends in populations of bull trout in the Flathead River basin of Montana. In our simulations skipping years of data resulted in little change to our estimates of risk, except for the brown trout population in the Yellowstone River. However, population predictions from our models were essentially non- 
Table 2. Percentage of Simulated Population Trajectories where Values Contained within the $80 \%$ Confidence Limit of the Mean Fell Below 70\% of the 20 Year, Average (Average Abundance). "All Years" Indicates that Parameters Estimated from Models Containing all the Data were Used to Simulate Population Trajectories. "Alternative years" Indicates that Parameters Estimated from Models Containing Alternative Years of Data were Used to Simulate Population Trajectories

\begin{tabular}{|c|c|c|c|c|}
\hline \multicolumn{2}{|c|}{} & All Years & Alternate Years \\
\hline \hline River & Species & Mean Abundance & \% of Simulations< Threshold & \% of Simulations< Threshold \\
\hline Missouri & brown & 4751 & $43 \%$ & $43 \%$ \\
\hline & rainbow & 4796 & $2 \%$ & $<1 \%$ \\
\hline Yellowstone & brown & 1805 & $32 \%$ & $40 \%$ \\
\hline Madison & rainbow & 1015 & $40 \%$ & NA \\
\hline & brown & 3717 & $13 \%$ & $17 \%$ \\
\hline
\end{tabular}

Table 3. Results of Simulation Models Based on Observed Data, Determining the Percentage Runs Out of 1000 Simulations that Produced Statistically Significant Trend Estimates given a Set Population Decline Over a 5 Year Period. CV Range $=$ Coefficient of Variation Range for the Estimated Population Means

\begin{tabular}{|c|c|c|c|c|c|}
\hline & & & \multicolumn{3}{|c|}{ Percent Decline } \\
\hline \multirow[t]{2}{*}{ Missouri } & brown & $5-9 \%$ & $73.60 \%$ & $98.40 \%$ & $100 \%$ \\
\hline & rainbow & $18-49 \%$ & $14.30 \%$ & $23.50 \%$ & $49 \%$ \\
\hline Yellowstone & rainbow & $7-35 \%$ & $29.90 \%$ & $59.30 \%$ & $88.40 \%$ \\
\hline \multirow[t]{2}{*}{ Madison } & brown & $9-27 \%$ & $28.60 \%$ & $57.30 \%$ & $88.60 \%$ \\
\hline & rainbow & $7-35 \%$ & $30.10 \%$ & $60.70 \%$ & $85.50 \%$ \\
\hline
\end{tabular}

informative (i.e., had wide credible intervals). Many authors have suggested that increasing the precision of estimates should be a goal of any monitoring program [33, 34], and that managers should not be wary of skipping years of data in order to increase the precision of estimates in alternate years [6, 9]. In our analysis we "borrowed" information across years within a site to estimate the detection function and improve estimates of recapture efficiency for years with sparse data.

Our inability to detect statistically significant densitydependent effects for most species in most rivers (i.e. where estimates of the density dependent term in the Gompertz model were statistically different from zero) may be the result of our data covering too short of a time frame for effects to be detected statistically [35], or the overall uncertainty in our parameter estimates. Additionally, for rainbow trout in the Yellowstone and Missouri river reaches, Gompertz models displayed a lack of fit and a tendency to estimate high and low observations closer to the mean. Gompertz models may not be the appropriate model for these species, in these river reaches. Modeling sources of variation such as weather, abundance of other species, or flow rates on abundance and capture efficiency may allow managers to gain more accurate and precise estimates, and/or develop a greater under- standing of the process driving the population dynamics of trout species.

Estimating population trend is often a goal of fish managers. However, our inability to detect declines of $30 \%$ or $50 \%$ over a five-year period is not surprising, and reflects the large amount of uncertainty associated with our estimates. Managers often want to know a short term < 5-year trend; however, longer-term data sets are usually necessary to detect even precipitous declines [33, 34]. For example, Wildhaber et al., [36] determined that 10-20 years of data were necessary to detect a $5 \%$ annual decline in catch per unit effort of two sturgeon species. Estimating trends in fish abundance requires accurate estimates of population numbers in order to avoid concluding that changes in population counts are due to population changes and not changes in the observation process. Accurately enumerating fish and wildlife populations is a notoriously difficult statistical problem, which should not be ignored when designing monitoring programs.

Evaluating monitoring programs on the power of the sampling to detect trends may not be the best metric [33]. There are many assumptions that have to be made in order to determine the statistical power of any particular analysis. For example, our ability to detect a trend assumed that a signifi- 
cant decline in the population would not correspond with a simultaneous change in the $\mathrm{CV}$ of the population estimates. Trend analysis may provide management with useful information regarding the trajectory of a population regardless of the statistical significance of the trend; however, for most populations determining what magnitude of change represents a biologically significant change is a difficult task.

Monitoring programs should be designed carefully to ensure adequate sample size to estimate the population metric of interest, [33, 34, 37] and in some cases annual surveys should be abandoned if necessary to increase the length of the time series or the intensity of the sampling [8]. Dauwalter et al., [38] demonstrated a variety of sampling designs that had similar statistical power to detect declines in trout biomass over time. In Montana, conducting fish monitoring less frequently but with greater intensity might be better for trend evaluation, if that meets the objectives for monitoring. Improved precision of estimates would have increased our ability to detect trends. Sampled reaches within a particular Montana river could be combined to increase the number of replicates for a particular river, thereby increasing the number of monitoring sites and potentially improving precision [38]. However, determining the spatial scale of the trout populations is necessary prior to combining sites or increasing the number of replicates. A better understanding of how species distributional factors change over time and space would provide valuable information to improve sampling designs for future trout population estimates [39]. Replication of sites in ecological studies is always difficult, and even within the same river system, populations at different sites may be different enough that variability of a river-wide population estimate would only increase when sites are added.

Identification of monitoring objectives is essential in designing a monitoring protocol that provides a cost-effective way meeting management needs. Defining the objectives of the monitoring program in the context of a decision-making strategy is the first step toward developing an effective sampling design that will provide managers with the information they need to make informed decisions [40]. Monitoring is necessary when decisions are based on the "state" of the system which is often the population size of the species in question [41]; however, monitoring may be more critical when the state of the system is uncertain and predictions from population models contain too much variability to be informative [6]. Developing and testing predictive population models is an essential step toward an improved understanding of trout population dynamics and a more cost-effective monitoring program. An accurate and reliable predictive model could be developed and used to estimate populations in years when sampling does not take place, allow managers to determine the circumstances under which model predictions are most uncertain, and monitoring is most necessary.

\section{ACKNOWLEDGEMENTS}

Montana Fish, Wildlife \& Parks' employees and volunteers contributed greatly to the collection of the fish monitoring data sets. J. Andrew Royle at Patuxent Wildlife Resources Center provided assistance with $\mathrm{R}$ code, a review and helpful discussions. Jay Rotella at Montana State University and Elise Zipkin at Patuxent Wildlife Resources Cen- ter also provided a reviews that greatly improved the manuscript.

\section{CONFLICT OF INTEREST}

None Declared.

\section{REFERENCES}

[1] Duffield J, Loomis J, Brooks R. The net economic value of fishing in Montana. Helena: Montana Fish, Wildlife, and Parks 1987.

[2] Boyd JW, Guy CS, Horton TB, Leathe SA. Effects of catch-andrelease angling on salmonids at elevated water temperatures. North Am J Fish Manag 2010; 30: 898-907.

[3] Bartholomew JL, Reno PW. The history and dissemination of whirling disease. In: Bartholomew JL, Wilson JC, Eds. Whirling disease: reviews and current topics. Bethesda: American Fisheries Society Symposium 2002; pp. 3-24.

[4] Nichols JD, Williams BK. Monitoring for conservation. Trends Ecol Evol 2006; 21: 668-73.

[5] Lindenmayer DB, Likens GH. Adaptive monitoring: a new paradigm for long-term research and monitoring. Trends Ecol Evol 2009; 24: 482-6.

[6] Hauser CE, Pople AR, Possingham HP. Should managed populations be monitored every year? Ecol Appl 2006; 16: 807-19.

[7] Lindén A, Knape J. Estimating environmental effects on population dynamics: consequences of observation error. Oikos 2009; 118 : 675-80.

[8] Clark JS, Bjørnstad ON. Population time series: process variability, observation errors, missing values, lags, and hidden states. Ecology 2004; 85: 3140-50.

[9] Humbert JY, Mills LS, Horne JS, Dennis B. A better way to estimate population trends. Oikos 2009; 118: 1940-6.

[10] Ricker WE. Computation and interpretation of biological statistics of fish populations. Fish Res Board Canada Bull 1975; 191: 1-382.

[11] Seber GAF. The estimation of animal abundance and related parameters. Caldwell, NY: Blackburn Press 1982.

[12] Nordwall F. Movements of brown trout in a small stream: effects of electrofishing and consequences for population estimates. North Am J Fish Manage 1999; 19: 462-9.

[13] Kendall WL. Robustness of closed capture-recapture methods to violations of the closure assumption. Ecology 1999; 80: 2517-25.

[14] Cressie N, Calder CA, Clark JS, Ver Hoef JM, Wikle CK. Accounting for uncertainty in ecological analysis: the strengths and limitations of hierarchical modeling. Ecol Appl 2009; 19: 553-70.

[15] MacKenzie DI, Kendall WL. How should detection probability be incorporated into estimates of relative abundance? Ecology 2002; 83: 2387-93.

[16] Royle JA, Dorazio RM. Hierarchical modeling \& inference in ecology, the analysis of data from populations, metapopulations and communities. San Diego: Academic Press 2008; pp. 444.

[17] Peterson NP, Cederholm CJ. A comparison of the removal and mark-recapture methods of population estimation for juvenile coho salmon in a small stream. North Am J Fish Manage 1984; 4: 99102 .

[18] Bohlin T, Hamrin S, Heggeber TG, Rasmussen G, Saltveit SJ. Electrofishing-theory and practice with special emphasis on salmonids. Hydrobiologia 1989; 173: 9-43.

[19] Dalbey SR, McMahon TE, Fredenberg W. Effect of electrofishing pulse shape and electrofishing-induced spinal injury on long-term growth and survival of wild rainbow trout. North Am J Fish Manage 1996; 16: 560-9.

[20] Dwyer WP, Shepard BB, White RG. Effect of backpack electroshock on westslope cutthroat trout injury and growth 110 and 250 days posttreatment. North Am J Fish Manage 2001; 21: 646-50.

[21] Robson DS, Reiger HA. Sample size in Peterson Mark Recapture Experiments. Trans Am Fish Soc 1964; 93: 215-26.

[22] Vincent R. River electrofishing and fish population estimates. Prog Fish Cult 1971; 33: 163-9.

[23] Peterson JT, Thurow RF, Guzevich J. An evaluation of multipass electrofishing for estimating the abundance of stream-dwelling salmonids. Trans Am Fish Soc 2004; 133: 462-75.

[24] Johnson DH. In defense of indices: the case of bird surveys. J Wildl Manage 2008; 72: 857-68. 
[25] Gelman A, Carlin JB, Stern HS, Rubin DB. Bayesian data analysis $2^{\text {nd }}$ ed., Boca Raton, FL: Chapman \& Hall/CRC 2004.

[26] Royle JA, Young KV. A hierarchical model for spatial capturerecapture data. Ecology 2008; 89: 3233-44.

[27] Dennis B, Ponciano JM, Lele SR, Taper ML, Staples DF. Estimating density dependence, process noise, and observation error. Ecol Monogr 2006; 76: 323-41.

[28] Taper ML, Staples DF, Shepard BB. Model structure adequacy analysis: selecting models on the basis of their ability to answer scientific questions. Synthese 2008; 163: 357-70.

[29] Ricker WE. Stock and recruitment. J Fish Res Board Can 1954; 11: $559-623$.

[30] Mac Nally R, Thomson JR, Kimmerer WJ, et al. Analysis of pelagic species decline in the upper San Francisco Estuary using multivariate autoregressive modelling (MAR). Ecol Appl 2010; 20: 1417-30.

[31] Dennis B, Taper ML. Density dependence in time series observations of natural populations: estimation and testing. Ecol Monogr 1994; 64: 205-24.

[32] Staples DF, Taper ML, Shepard BB. Risk-Based Viable Population Monitoring. Conserv Biol 2005; 19: 1908-16.

[33] Seavy NE, Reynolds MH. Is statistical power to detect trends a good assessment of population monitoring? Biol Conserv 2007; 140: 187-91.
[34] Dauwalter DC, Rahel FJ, Gerow KG. Temporal variation in trout populations: implications for monitoring and trend detection. Trans Am Fish Soc 2009; 138: 38-51.

[35] Wolda H, Dennis B.. Density dependence tests, are they? Oecologia 1993; 5: 581-91.

[36] Wildhaber ML, Holan SH, Bryan JL, Gladish DW, Ellersieck M. Assessing power of large river fish monitoring programs to detect population changes: the Missouri river sturgeon example. J Appl Ichthyol. 2011; 27: 282-90.

[37] Urquhart NS, Kincaid TM. Designs for detecting trend from repeated surveys of ecological resources. J Agric Biol Environ Stat 1999; 4: 404-14.

[38] Dauwalter DC, Rahel FJ. Power of revisit monitoring designs to detect forestwide declines in trout populations. North Am J Fish Manage 2010; 30: 1462-8.

[39] Cowx IG, Harvey JP, Noble RA, Nunn AD. Establishing survey and monitoring protocols for the assessment of conservation status of fish populations in river Special Areas of Conservation in the UK. Aquat Conserv 2009; 19: 96-103.

[40] Williams BK, Szaro RC, Shapiro CD. Adaptive management: the U.S. Department of Interior Technical Guide. Washington, D.C. U.S. Dept of Interior 2007.

[41] Pollock KH, Nichols JD, Simons TR, Farnsworth GL, Bailey LL, Sauer JR. Large scale wildlife monitoring studies: statistical methods for design and analysis. Environmetrics 2002; 13: 105-19.

Received: June 23, 2011

Revised: October 07, 2011

Accepted: October 10, 2011

(C) Russell et al.; Licensee Bentham Open.

This is an open access article licensed under the terms of the Creative Commons Attribution Non-Commercial License (http://creativecommons.org/licenses/ by-nc/3.0/) which permits unrestricted, non-commercial use, distribution and reproduction in any medium, provided the work is properly cited. 